\title{
Spiral path three phase fluidized bed reactor for treating wastewater contaminated with engine oil
}

\author{
Abeer I. Alwared ${ }^{1} \cdot$ Wisam Sh. Jaber ${ }^{2}$ \\ Received: 20 May 2020 / Accepted: 31 July 2020 / Published online: 19 August 2020 \\ (C) The Author(s) 2020
}

\begin{abstract}
In this study, a new type of circulating three-phase fluidized bed reactor was conducted by adding a spiral path and was named as spiral three-phase fluidized bed reactor (TPFB-S) to investigate the possibility for removing engine oil (virgin and waste form) from synthetic wastewater by using Ricinus communis (RC) leaves natural and activated by $\mathrm{KOH}$. The biosorption process was conducted by changing particle diameter in the range 150-300 and 300-600 $\mu \mathrm{m}$, liquid flow rate in the range $2.5-4.5 \mathrm{~L} / \mathrm{min}$ and gas flow rate in range of $0-1 \mathrm{~L} / \mathrm{min}$, while other parameters initial oil emulsion concentration, $\mathrm{pH}$, adsorbent concentration, agitation speed and contact time were kept constant at $2000 \mathrm{mg} / \mathrm{L}, 2,400 \mathrm{mg} / \mathrm{L}, 200 \mathrm{rpm}$ and 90 min, respectively. Both FTIR and SEM tests showed that the Ricinus communis surface contains of active and strong groups; therefore, it shows a morphological characteristic of interest. The tests of FTIR and SEM explained that the adsorbent solid texture consists of negative valences that related to strong and active groups like carboxyl and hydroxyl groups. Furthermore, the results showed that the removal efficiency reaches about 91 and $98 \%$ for both virgin and waste oil at 150-300 $\mu \mathrm{m}$ particle size, $3.5 \mathrm{l} / \mathrm{min}$ liquid phase flow rate and $1 \mathrm{~L} / \mathrm{min}$ air flow rate and for $90 \mathrm{~min}$ by using natural and activated form of RC leaves, respectively. In addition, results revealed that $95 \%$ of oil was recovered from the adsorbent by using $150 \mathrm{~mL} / \mathrm{L}$ of hexane. Finally the results concluded that TPFB-S has a better performance than the traditional fluidized bed, where the removal efficiency was enhanced by about $23 \%$ and $17 \%$ for removing virgin oil emulsion from aqueous solution by natural and activated form of adsorbent, respectively.
\end{abstract}

Keywords Engine oil · Ricinus communis leaves $\cdot$ Adsorption $\cdot$ Three-phase fluidized bed reactor

\section{Introduction}

Various pollutants are emerging in our environment. One of the pollutants that can cause an environmental problem is the presence oil and grease inside water system. Oil can contaminate the water in two different forms which are in the form of emulsified oil or the form of free oil. Once oil wastewater is introduced into aquatic environments in high

Abeer I. Alwared

abeerwared@yahoo.com;

dr.abeer.wared@coeng.uobaghdad.edu.iq

Wisam Sh. Jaber

w2011222@gmail.com

1 Department of Environmental Engineering, University of Baghdad, Baghdad, Iraq

2 Department of Civil Engineering, University of Babylon, Baghdad, Iraq concentration, it becomes toxic to the aquatic life and damages other ecology in water bodies (Abdul Hamid et al. 2016).

Lubricating oil is the most famous type of petroleum fraction that used in different vehicles and generators. Using of lube oil decreases friction between surfaces of moving parts. After oxidation of oil has been occurred, the impurities are formed in the base oil, which can happen due to the internal combustion inside the engine (Osman et al. 2018).

More than 30.3 billion liters of waste oil are generated yearly. Vehicles' engines are the major source of the waste oil. This waste of lubricant oil contains high hazardous essential from carbon residue, ash, materials asphaltenes, metals and other unclean materials formed during lubricants in the machine. The disposing of waste oils directly toward the environment can lead to severe problems; the problems can take place in seas, rivers and lakes, and the contamination can effect negatively on water resources and marine life (Riyanto et al. 2018). Oily wastewater contains toxic 
substances such as phenols, petroleum hydrocarbons and polyaromatic hydrocarbons, which are inhibitory to plant and animal growth, equally, mutagenic and carcinogenic to human being. Similarly, oily wastewater contains high oil content, chemical oxygen demand (COD) and color (Alade et al. 2011). Oil and grease is defined as a group of related materials rather than a specific chemical compound extractable by certain solvents, such as hexane (USEPA 1999). They are nonpolar and, as a result, are hydrophobic in nature (Travis et al. 2008). Generally, oil is not soluble in the water phase and the nature of the oil phase in oily wastewater is different from one case to another. Under anaerobic conditions, oils and grease hydrolyze to long chain fatty acids (LCFA) and glycerol. The glycerol further degrades to 1, 3-propanediol and subsequently to acetate. Oil-water mixture with droplets greater than or equal to 150 microns is classified as free oil, while oil-water mixture with droplets size ranging between 20 and 150 microns is classified as dispersed oil mixture. Emulsified oil mixture is oil-water mixture with droplet sizes smaller than 20 microns, and oil-water mixture with droplet sizes smaller than 5 microns is classified as soluble oil mixture (Alade et al. 2011).

Surfactants are chemical compounds that include both hydrophobic and hydrophilic properties, and they have been used in a different type of commercial products such as detergents. When surfactants mix with oil-water mixtures, then the hydrophilic zone of the surfactants moves toward the water phase, while the hydrophobic part of the molecular move toward the oil phase (Vu and Papavassiliou 2018), leading to reduction of the surface tension of oil drops and separation of them in solution. The separation of oil can be enhanced when mixing force is founded like high flow rate or high pressure (Krstonosic et al. 2012).

Oily wastewater has made several problems in environment due to its hazardous nature. The amount of oily wastewater has become in huge amount; one of the reasons is the petroleum stations that still supply for the growing number of cars. In Iraq, there are more than 500 car service facilities, and some of these stations discard their wastewater in emulsion form toward the sewers without any treatment (Mustafa et al. 2013). There are many methods for the separation of oil-water emulsions, such as variety of filters (Cumming et al. 1999), biological processes (Parhamfar et al. 2018), membrane bioreactor (Capodici et al. 2017), electrocoagulation and electroflotation (Ji et al. 2015) and adsorption (Abdul Hamid et al. 2016) and air flotation (Sulaymon and Mohammed 2010; Alwared and Faraj 2015), and each of the methods has their advantages and disadvantages.

Adsorption is a universal, attractive, simple and effective treatment method that can be used for the remediation of the contaminants present in aqueous solutions (Mohammed et al. 2018; Khodadadi et al. 2019), which is characterized by high oil removal efficiency, low cost and low in processing cost. However, there are also some disadvantages in using adsorption methods; it required labor intensive and poor removal of fine emulsions (Abdul Hamid et al. 2016). Biosorbents fall under the following categories: bacteria, yeast, fungi, algae and industrial and agricultural wastes (Kamar et al. 2016). A wide range of a biosorbent material had been used in the treatment of oily wastewater; such as bentonite (Okiel et al. 2010), egg shell (Abdel-Jabbar et al. 2010) and potato peels (Tontiwachwuthikul et al. 2016).The biosorption in columns and its modeling have been receiving more attention. Fixed and fluidized bed reactors have been used widely by the chemical industry, pharmaceutical industry, food industry, wastewater treatment and for recovery of different substances Fluidized bed systems are common and important reactors in process engineering because of the good mass and heat transfer rate between the fluid and the particles, and between the particles and the side wall of the column (Sulaymon et al. 2013a, b).

In gas, liquid, and solid circulating fluidized beds reactor, the adsorbent is circulated between the downer and the riser in which the adsorption process occurs in the riser while the desorption process occurs in the downer column which increase contact efficiency between liquid-solid, operated continuously (adsorption and desorption work simultaneously that the particles circulated between two separate columns), reduced back mixing of phases, greater throughput and improved mass transfer owing to the higher velocity and uniform flow pattern (Mohammed and Najim 2020).

The present work aimed to examine a novel technique of three-phase fluidized bed reactor, through adding a spiral path for removal of engine oil (virgin and waste) from aqueous solutions by using Ricinus communis (RC) particles as inexpensive and environmental-friendly adsorbent. The biosorption process was examined under the influence of various important parameters including particle size and flow rate.

\section{Materials and experimental work}

\section{Sorbent and chemicals}

Ricinus communis (RC) leaves, as shown in Fig. 1, organic sorbent, have been collected from one of the fields in Babylon province, Iraq. Leaves were cleaned several times with distilled water until no foreign color was noticed, dried in an oven at $100{ }^{\circ} \mathrm{C}$ for $24 \mathrm{~h}$ after that sieved to the desired size and stored in stoppered bottle until use. Brunauer-Emmett-Teller (BET) analysis was performed using Belsorp mini II instrument conducted according to ISO-9277-2010 in laboratories of Iraqi Petroleum Research and Development Center, which is revealed that the surface area of the used RC was found to be $11,175 \mathrm{~cm}^{2} / \mathrm{g}$. 
Table 1 General properties of fresh and waste oil

\begin{tabular}{lll}
\hline Property & Fresh oil & Used oil \\
\hline Specific gravity $\left(\mathrm{g} / \mathrm{cm}^{3}\right)$ & 0.887 & 0.773 \\
Flash point $(\mathrm{C})$ & 218 & 198 \\
Appearance & Light brown liquid & $\begin{array}{c}\text { Dark brown } \\
\text { to black } \\
\end{array}$ \\
& & liquid \\
\hline
\end{tabular}

Table 2 Properties of SDS surfactant

\begin{tabular}{ll}
\hline Property & SDS surfactant \\
\hline Chemical formula & $\mathrm{NaC}_{12} \mathrm{H}_{25} \mathrm{SO}_{4}$ \\
Molecular weight (g/mole) & 288 \\
Purity & $99 \%$ \\
Company & Fisher Scientific \\
\hline
\end{tabular}

Moreover, to elucidate the fundamental morphological characteristics of the RC, SEM images before and after adsorption of virgin and waste engine oil by $\mathrm{RC}$ particle was studied. Additionally, the active groups in solid surface were evaluated using Fourier transform infrared (FTIR) analysis, where the FTIR spectra were made using FTIR spectroscopy instrument (Shimadzu FTIR 8000 series).

- Engine oil type Hyundai ATF SP-III was used in this study, both of virgin and waste engine oil form, which was provided from a car station at Hilla city/Babylon, the car station serves at least 50 vehicle per day by replacing the used engine oil by a new one, and the oil used in this station was semi-synthesized type. The physical properties of engine oil were measured according to ASTM standard methods and GC-mass and are listed in Table 1

- Sodium dodecyl sulfate (SDS) was used as surfactant, the surfactant had both hydrophilic and hydrophilic ends, and the hydrocarbon tail attached oil molecules, while the sulfate and sodium end had been attached to water molecules. Table 2 lists the main properties of the SDS.

- All the chemicals used in this study were of analytical grade. The value of $\mathrm{pH}$ of the solutions was fixed to desire magnitude by adding of $1 \mathrm{~mol} / \mathrm{l} \mathrm{NaOH}$ or $\mathrm{HCl}$ by using a pH meter (WTW, inoLab 720, Germany).

- The desired concentrations of oil emulsion were by injecting the required volume of oil and SDS into specific volume of distilled water and then stirring at $200 \mathrm{rpm}$ for about 15 min after that mixing; oil drops disappeared from water surface and water solution, and then, milklike solution was obtained, which exhibited the characteristics of chemically stabilized solution. Diameter distribution of the emulsion was measured at different time intervals to ensure the stability using microscope, and the scanning cycles were set to three times to ensure the accuracy.

\section{Experimental work}

The experimental work was implemented in a continuous system using three-phase fluidized bed with spiral path reactor (TPFB-S), which consists of two parts: the riser $(9 \mathrm{~cm}$ diameter, height of $50 \mathrm{~cm}$ and capacity of $3.5 \mathrm{~L}$ ) connected to a cone of $7 \mathrm{~cm}$ height and then connected to a column of $12.5 \mathrm{~cm}$ diameter for mixing the three phases. The second part is the spiral path $(12.5 \mathrm{~cm}$ diameter contained a helical tube with $13.8 \mathrm{~m}$ length and 3.6L capacity), which then moved downward joining with the starting point of flow. The treatment unit contained emergency air outlet at the top of the riser which can be used to decrease the air fraction if pressure drop occurred; Fig. 2 shows a schematic diagram and photographic of the experimental device, respectively.

Different parameters were studied in reactor such as particle size at the range of 150-300 $\mu \mathrm{m}$ and 300-600 $\mu \mathrm{m}$, flow rate and operation time for the removal of virgin and waste engine oil emulsion in aqueous solution, while keeping other parameters constant from previous batch experiments (400 mg/L concentration of adsorbent, 90-min contact time
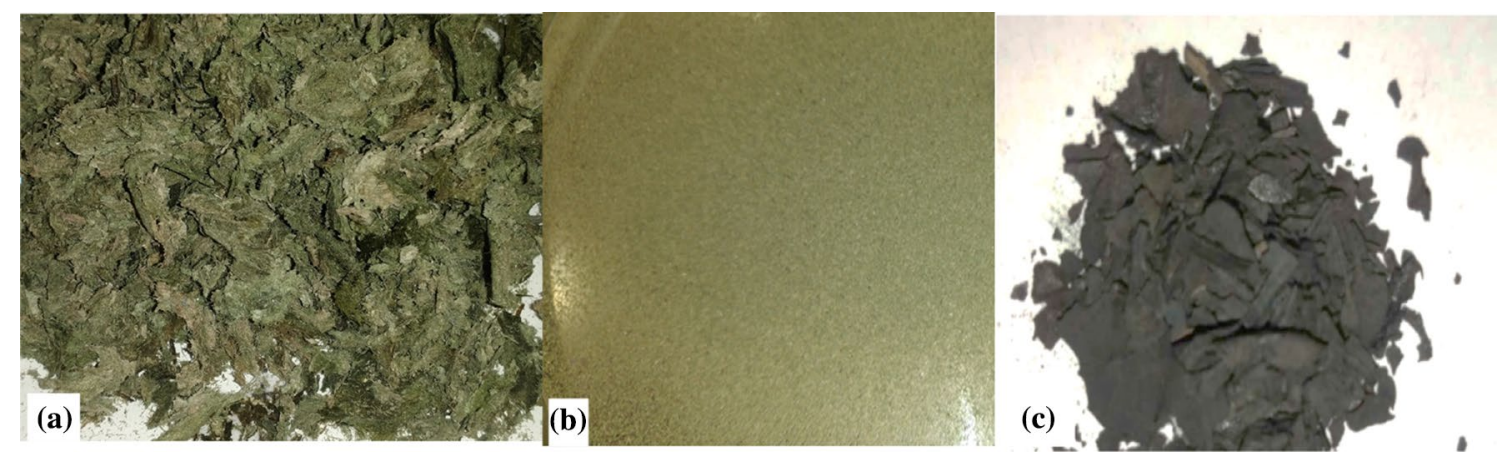

Fig. 1 Ricinus communis leaves a before grinding and sieving, $\mathbf{b}$ after grinding and sieving and $\mathbf{c}$ after activation by KOH 


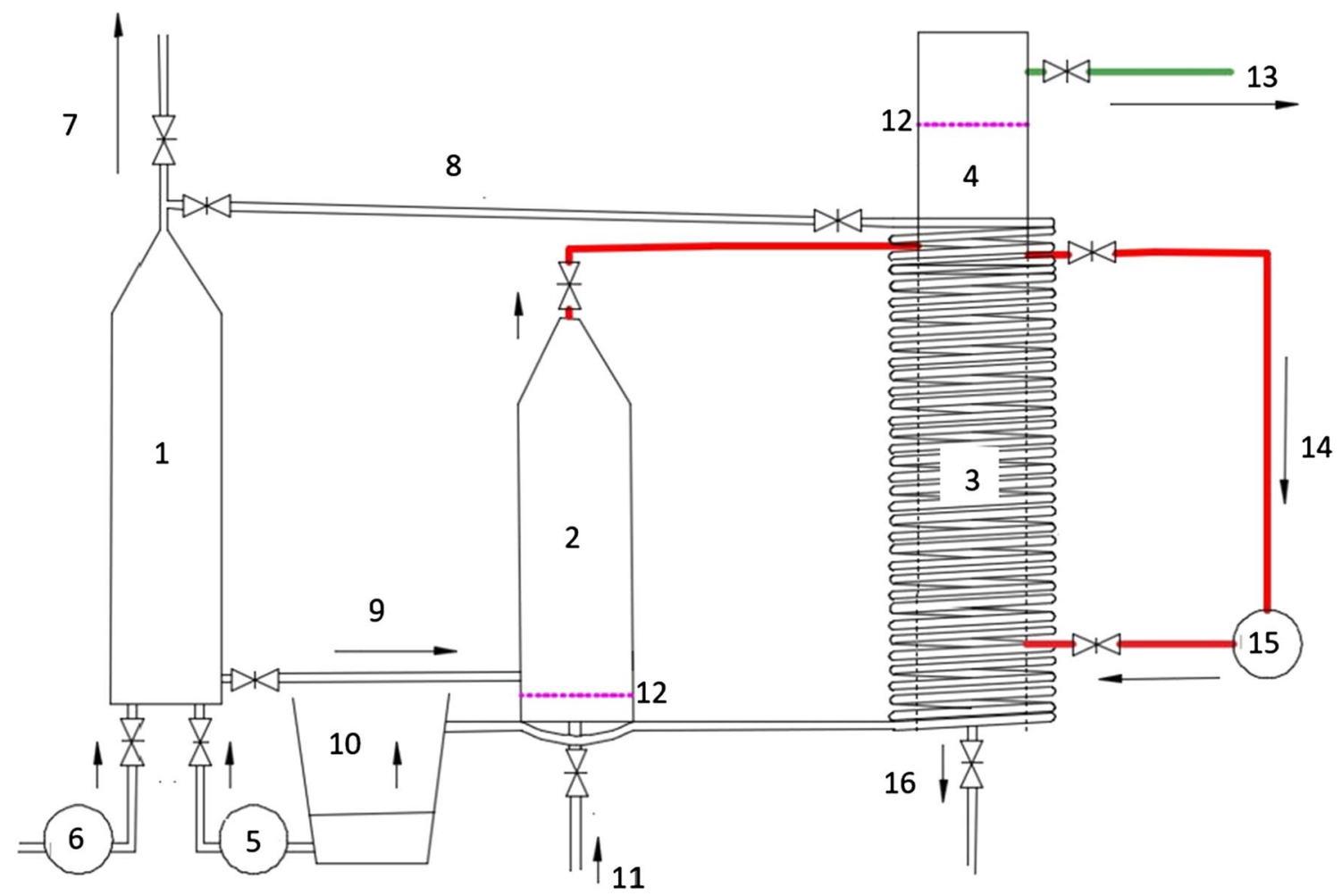

Fig. 2 Schematic diagram of three-phase fluidized bed reactor: (1) riser column, (2) separator column, (3) spiral tube, (4) desorption column, (5) electrical pump for liquid phase inlet, (6) electrical pump for gas phase inlet, (7) emergency air outlet, (8) outlet of phases from riser toward spiral tube, (9) outlet of phases from riser toward

and acidified solution $(\mathrm{pH}<2))($ Jaber and Alwared 2019). The minimum inlet velocity that causes fluidization of the solid particles was investigated by testing different inlet velocities placing on a specific amount of solid particles placed at the bottom of the reactor. At specific time intervals of each test, a sample was withdrawn from end point of the spiral zone, filtered and then analyzed for oil content using liquid extracted method (EPA 1664A method).

\section{Desorption of oil}

The recovery of oil from solid surfaces of adsorbent was achieved by using the desorption column as shown in Fig. 3 ; in this stage, the mixture of solid particles that contained adsorbed oil molecules had been discharged to the desorption column that came from the separator in the second stage, and after that, pure hexane solution was added to the mixture in specific amount, the new mixture was looped many times to ensure completion of mass transfer of oil molecules from the adsorbent to be dissolved in hexane, then the mixture leaved to be stable, the hexane layer is noticeable on the top of solution, the column had steel filter near the upper point, amount of distilled water was used to raise the separator column, (10) gas phase outlet, (11) distilled water inlet to separator column, (12) 125-micron filter, (13) outlet of solvent after extraction, (14) recycling of liquid and solid phases with solvent for desorption column, (15) electrical pump for phases recycling in desorption column, (16) outlet of particles after desorption

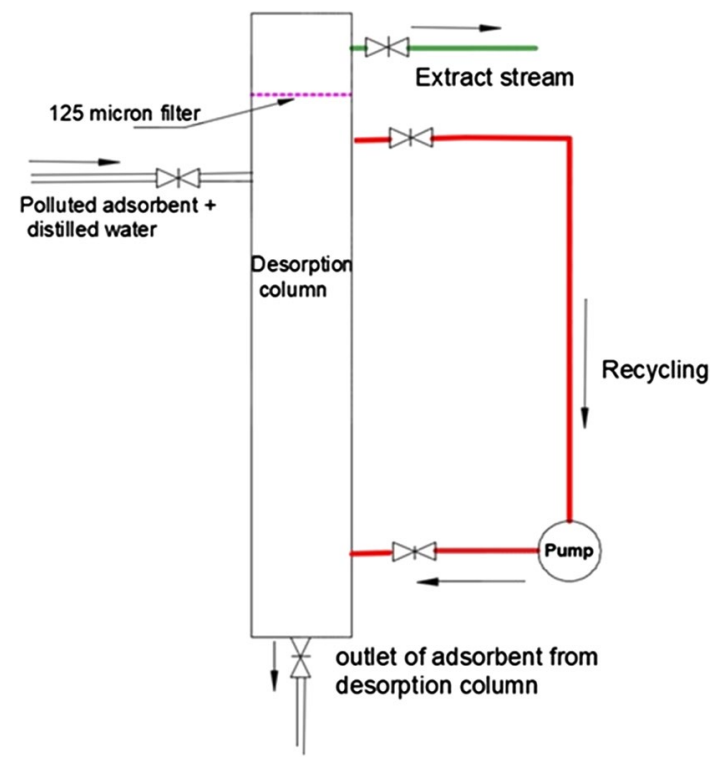

Fig. 3 Desorption column

hexane layer to be above the sieve elevation so that it was easily moved out the column to be collected, and the solution 
then heated for evaporation of hexane, to get the remaining matter which represented the adsorbed oil.

\section{Results and discussion}

\section{GC-MS test}

The chemical compounds that form both types of engine oil were analyzed through GC-MS test, and the results as plotted in Fig. 4 reveal that the major part of the two forms of oil was aliphatic hydrocarbon which was saturated that made by single bond only (alkanes) or unsaturated compound that made by double bond (alkenes) and a number of aromatic hydrocarbon had been detected by the testing device. It can be seen from these results that different aromatic and aliphatic hydrocarbons were detected by the GC-MS device, and the results of analysis explained the complex mixture of both fresh and used oil.

\section{FTIR test}

The ability of $R C$ natural and activated by $\mathrm{KOH}$ in the case of before and after adsorption process was tested under FTIR test as shown in Fig. 5. Oil contains hydrocarbons such as aliphatic compounds as a major part and aromatic compounds and also contains non-hydrocarbons such as sulfur and nitrogen compounds (like sulfides, thiophene, pyridine and pyrrole) (Liang et al. 2018), function group of $\mathrm{C}=\mathrm{C}$ bond was noticed in the chart in the range 1440-1600. This bond was resulted by the attendance of aromatic compounds in the oil formula $(1,3,5$-cycloheptatriene and 2-methyl-6-propyl), the other function group recognized was $\mathrm{C}=\mathrm{C}$ of aliphatic compounds in the range of 1600-1650, the source of this bond could be (1,8-nonadiene, 2,7-dimethyl-5-(1-methylethenyl)-), and the $\mathrm{C}-\mathrm{H}$ bond of aliphatic hydrocarbons also noticed in the diagram in the range of 2850-2990. For the peak in the range 3200-3550, the hydroxyl group $(\mathrm{O}-\mathrm{H})$ was
Fig. 4 GC-MS test results for a virgin oil, $\mathbf{b}$ waste oil

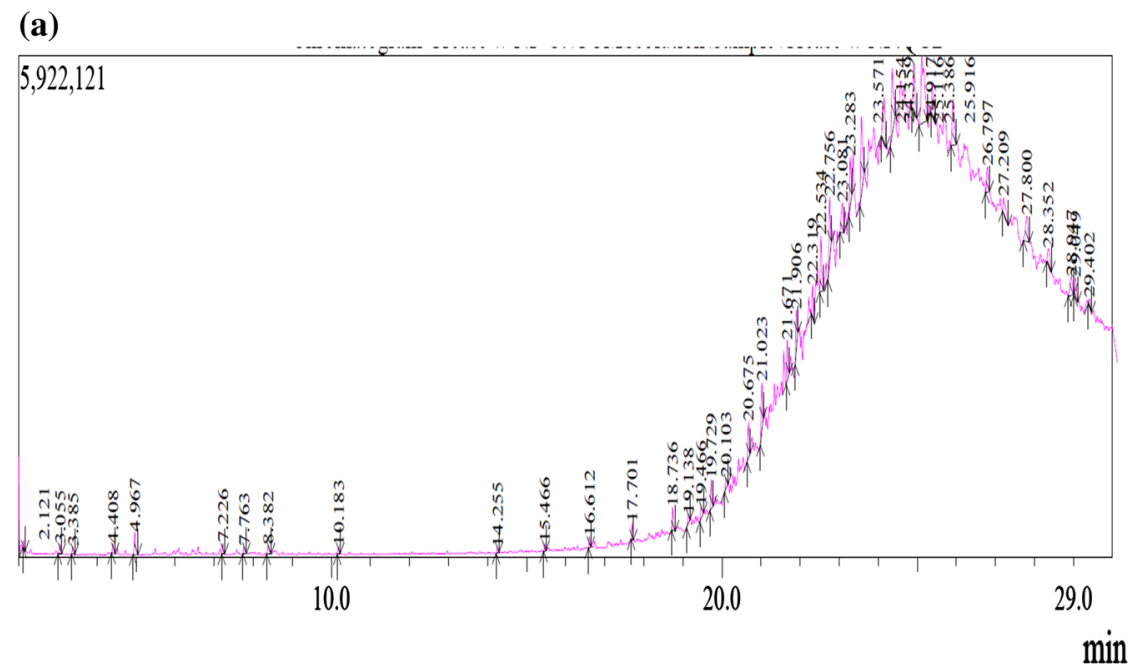

(b)

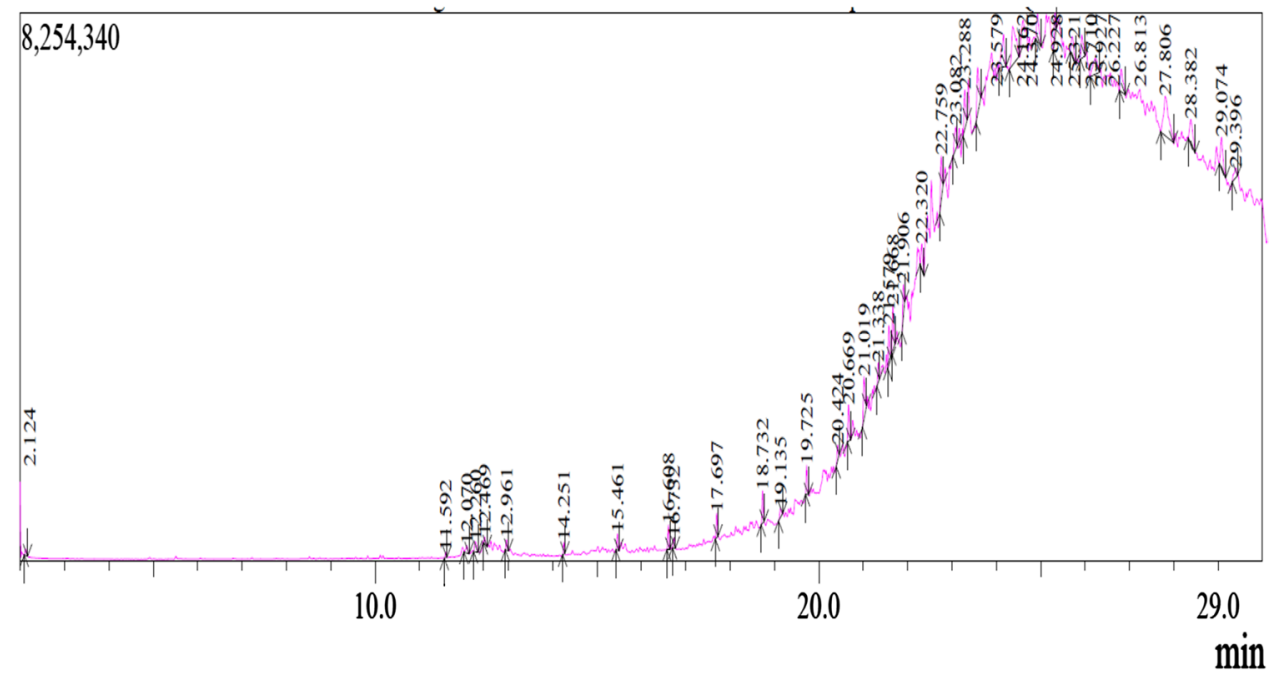




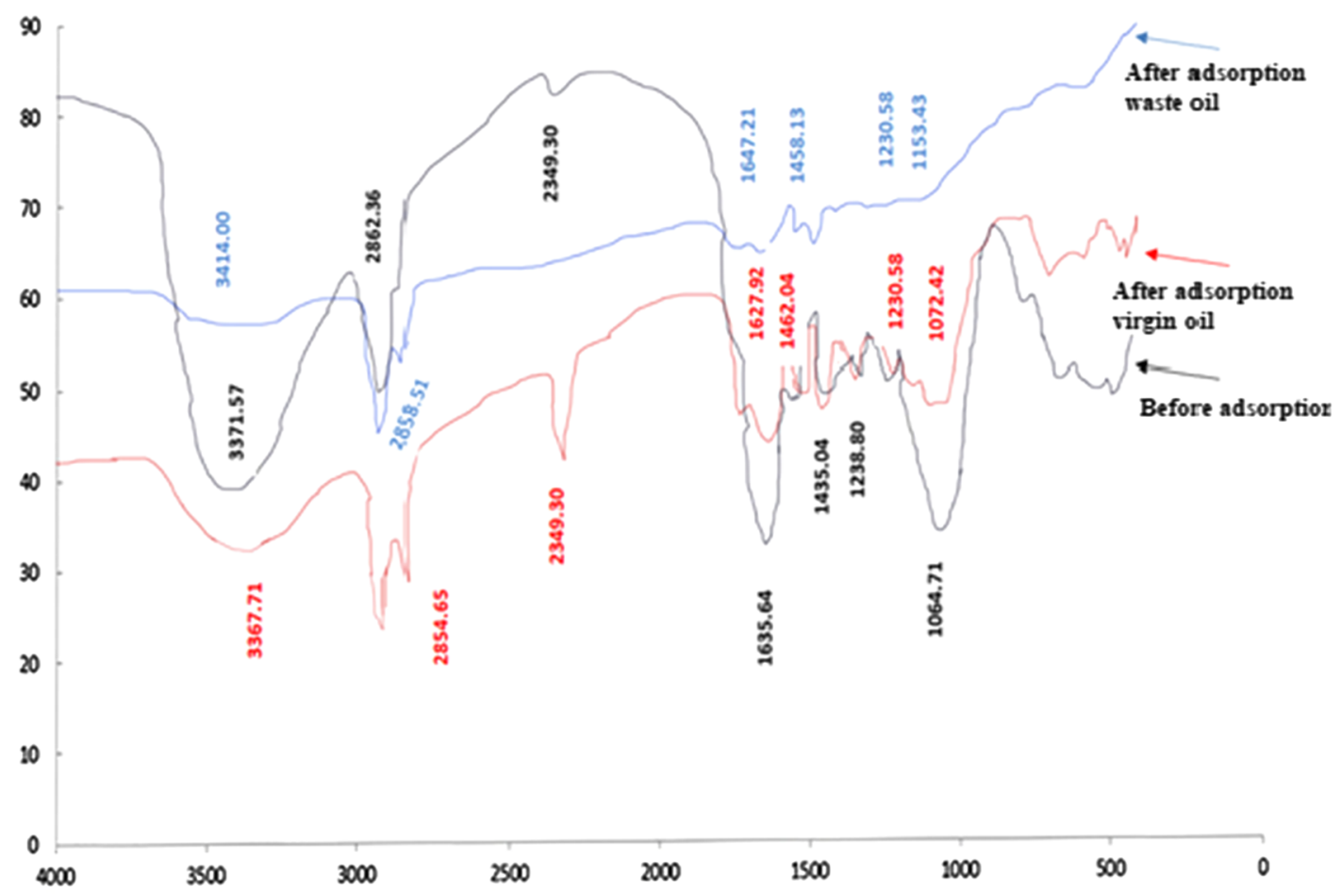

(a) Natural Ricinus

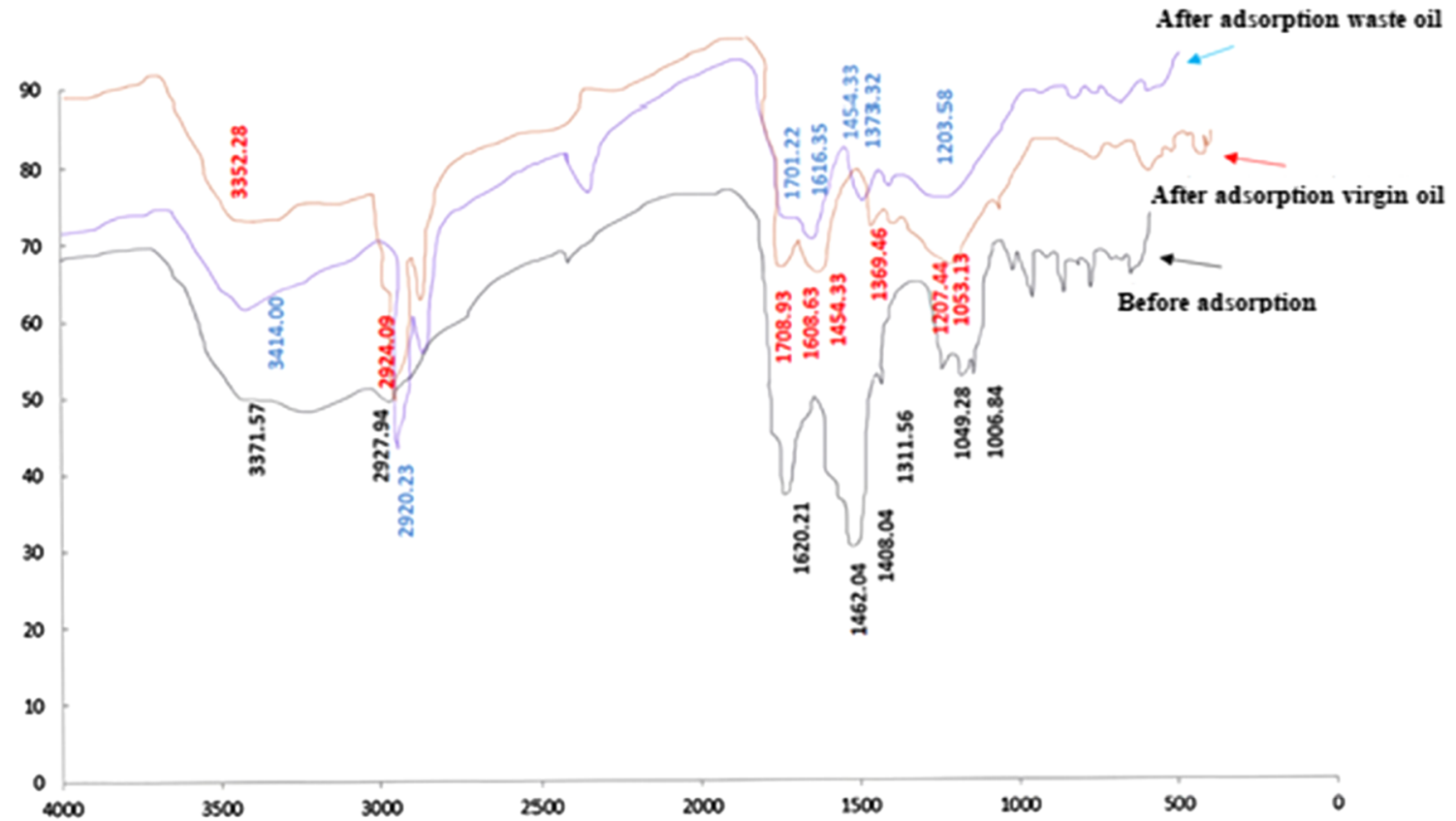

(b) Activated Ricinus

Fig. 5 FTIR test results

the reason by this peak which included in different compounds in oil like (2-isopropyl-5-methyl-1-heptanol and 1-dodecanol, 3, 7, 11-trimethyl-). When waste oil was used, new bonds appeared and the transmittance values $(\% \mathrm{~T})$ of various groups changed to new values, probably due to the interaction between these active sites with the 
oil components. The founding of aromatic hydrocarbons like (benzene-1,3-dimethyl-, benzene-1,2,4,5-tetramethyl-, and benzocycloheptatriene) indicating the appearance of peak in range of 1440-1625. The appearance of peak in the range of 1600-1650 was related to the aliphatic hydrocarbon (tetracosapentaene-2,6,10,15,19,23-hexamethyl-) as it contained the bond $(\mathrm{C}=\mathrm{C})$ in its formula, and the function group $\mathrm{C}-\mathrm{H}$ in aliphatic hydrocarbons was found in the range 2850-2990. The source of this function group was different compounds that included in waste oil structure like (hexadecane-7,9-dimethyl- and nonadecane-2-methyl-), hydroxyl group had been noticed in the range of 3200-3500, this function group was related to the compounds (phytol, 3-methyl-2-(3-methylpentyl)3-buten-1-ol, and octacosanol), and the carbon double bond with oxygen $(\mathrm{C}=\mathrm{O})$ had been found in the range 1705-1750 which relates to the compound (2-naphthalenol-1,2-dihydro-acetate). The FTIR spectra for $R C$ natural and activated were found to undergo significant changes. Consequently, the transmittance values ( $\% \mathrm{~T})$ of various groups changed to new values. Further, the shift in these groups after biosorption signified their role in the binding of different chemical compounds in the liquid-solid phase.

\section{SEM test}

To investigate the fundamental morphological characteristics of the two adsorbents used, SEM micrographs of RC (Fig. 6) were captured. The results revealed that the natural form of adsorbent contained fine grooves that enhanced the attachment of oil uptake, and similar structure is also found by (Mamoucha et al. 2017). After processing the adsorbent to modified form, the porosity increased noticeably the activated by $\mathrm{KOH}$ form appeared in the images with more fine porosity distributed overall the surface, the accumulative of oil portions can be seen clearly by the images related to the state after adsorption, and the pores covered by oil indicate the validity of using the plant in adsorption process.

\section{Minimum fluidized velocity}

The accurate knowledge of the hydrodynamic parameters is important for design and performance of fluidized bed reactor (Sulaymon et al. 2013a, b). One of the most important fundamental parameters in the design and analysis of fluidized beds is the minimum fluidization velocity (Hilal et al. 2001). It is not only set the lower limit to the flow rate of fluidized beds, but it is also one of the fundamental
Fig. 6 SEM test results for natural RC adsorbent (a: before, $\mathbf{b}$ : after) adsorption and activated $\mathrm{RC}$ adsorbent(c: before, $\mathbf{d}$ : after) adsorption
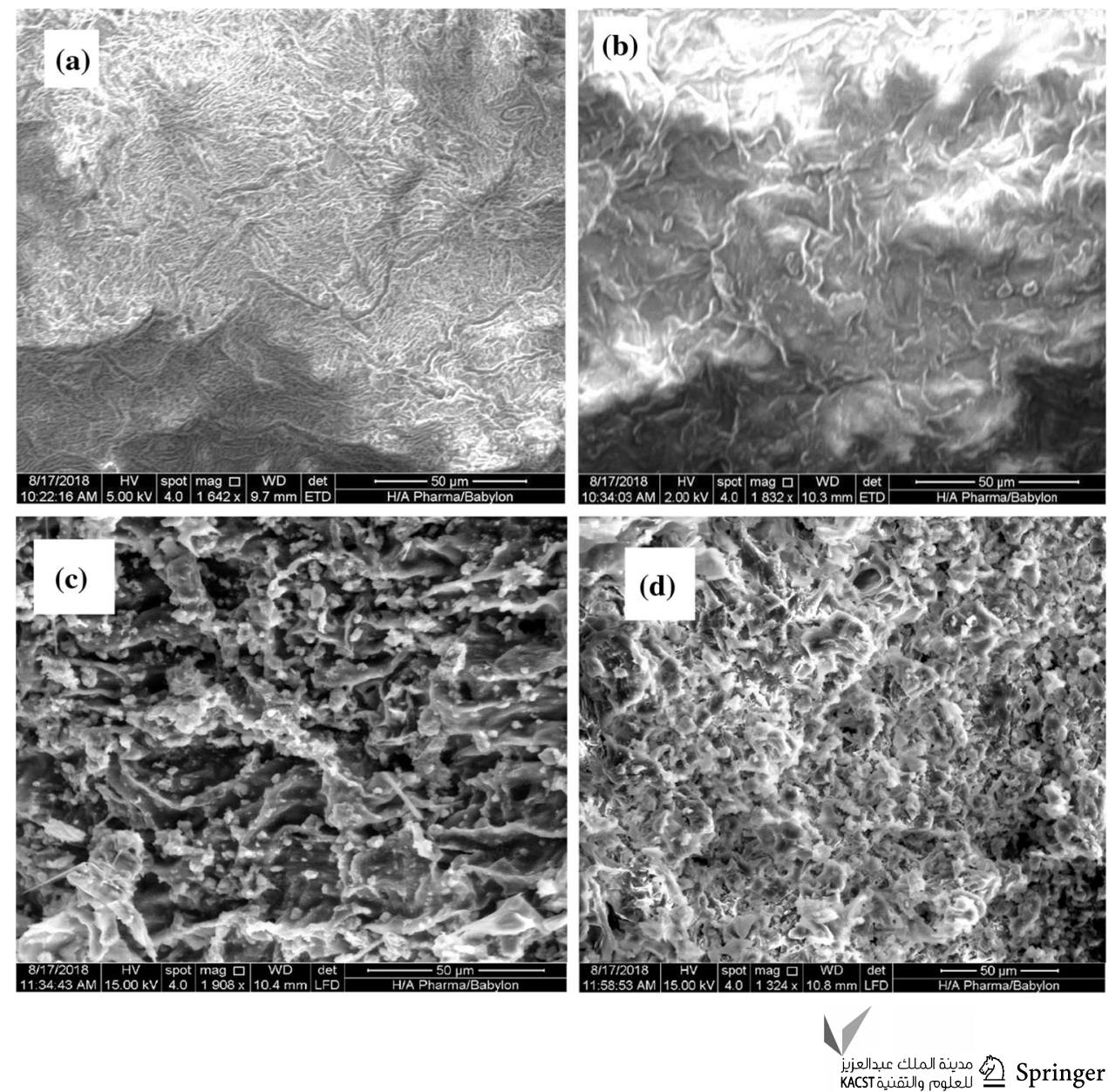
parameters in the modeling of biosorption-fluidized process. The minimum inlet velocity was recorded after placing of the particle bed and by slowly introducing liquid flow rate and increasing it gradually to different values from 0.0004 to $0.0012 \mathrm{~m} / \mathrm{s}$ at stagnant gas flow rate until any fluidization of the bed has been occurred; $0.0008 \mathrm{~m} / \mathrm{s}$ was registered as the minimum one for fluidizing, and according to Geldart diagram (Dechsiri 2004), the difference between the density of solid phase $\left(0.202 \mathrm{~g} / \mathrm{cm}^{3}\right)$ and density of solution $(0.998 \mathrm{~g} /$ $\mathrm{cm}^{3}$ ) was $0.796 \mathrm{~g} / \mathrm{cm}^{3}$ so that the particle with range size of $300-150$ micron considered as group A (aeratable) and so easy to fluidize.

\section{Particle size ranges}

The adsorption procedure was implemented in the continuous system for examining the ability of adsorption of Ricinus particles with different particle sizes (150-300 and 300-600) $\mu \mathrm{m}$ for both natural and activated form of RC adsorbent on the removal efficiency of virgin and waste oil from aqueous solution by natural and activated RC particles which are studied, and their results are presented in Fig. 7; this figure shows that the removal efficiency by activated RC was higher than that of natural form for all particle sizes. Further, the size of 150-300 $\mu \mathrm{m}$ shows higher removal efficiency for both natural and activated RC particles; this is due to decrease in the adsorbent specific surface area when particle size was increased (Alwared et al. 2020). Also as can be seen in Fig. 7, there is no clear difference between the removal efficiency of virgin and waste oil by natural or activated.

\section{Liquid flow rate}

The fluid flow rate is a major parameter for designing the biosorption column especially fluidized bed reactor due to its effect on the contact time between the particles and oil

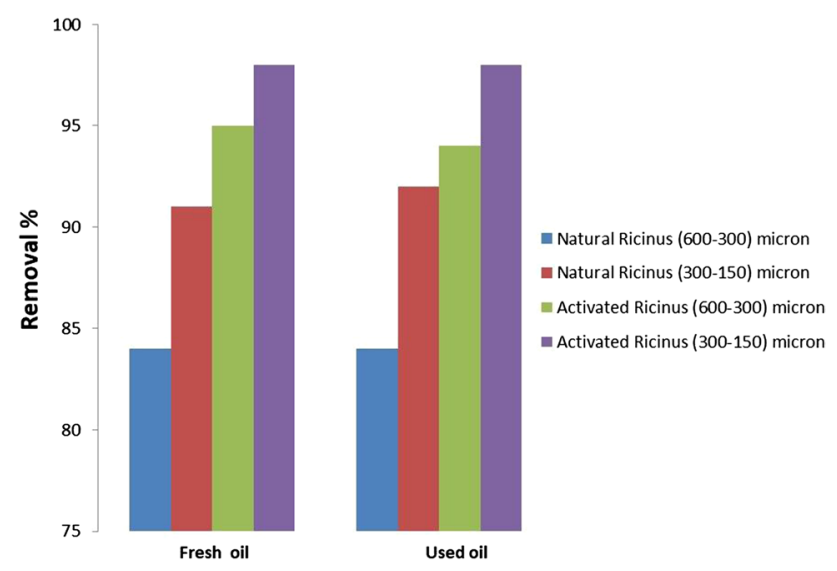

Fig. 7 Effect of RC particle size on the removal efficiency of oil emulsion by $\mathrm{RC}$ adsorbent emulsion solution. A different liquid flow was tested (2.5, 3.5 and $4.5 \mathrm{~L} / \mathrm{min})$ at stagnant air flow rate $(1 \mathrm{~L} / \mathrm{min})$ and keeping other parameters constant from batch experiments, and their results are plotted in Fig. 8. The results indicated that at the initial 18 min of the adsorption time, the adsorption occurred at a rapid rate. Subsequently, the process slowed in a gradual state; thereby, the system reached the equilibrium condition within $90 \mathrm{~min}$. Also, this figure shows that the removal efficiency increased by increasing liquid flow from 2.5 to 3.5. There was no significant change in the removal efficiency by increasing liquid flow rate from 3.5 to $4.5 \mathrm{~L} / \mathrm{m}$. Increasing liquid flow rate more than $4.5 \mathrm{~L} / \mathrm{min}$ leads to the formation of foam in the reactor path lines, and the amount of escaped air bubbles is less than those inside the solution due to the presence of surfactant in the solution which decreases the liquid velocity until closing the unit (Rossi and Cilliers 2000). The results of Fig. 8a and b show that there is no clear difference between the removal efficiency of virgin and waste oil by natural RC adsorbent, while it increased by about $7 \%$ when using activated RC instead of natural RC as can be seen in Fig. 8c and d.

\section{Air flow rate}

A different air flow rate varied from 0 to $1 \mathrm{~L} / \mathrm{min}$ was studied at constant liquid flow rate for both virgin and waste engine oil emulsion by RC adsorbent, and their results are plotted in Fig. 9. It can be seen from Fig. 9a that there is a slight increase in the oil removal efficiency by increasing air flow rate from 0 to $0.3 \mathrm{~L} / \mathrm{min}$ as compared with what happened by increasing the amount of inlet air from 0.3 to $1 \mathrm{~L} / \mathrm{min}$ for both virgin and waste oil, and also, this figure shows a small difference in the removal efficiency between virgin and waste oil at low air flow rate; this may be due to the presence of some impurities of waste oil mixture such as dust, heavy metals and waste metals from engine body (Abdel-Jabbar et al. 2010). However, when using activated RC instead of natural RC, the same behavior was noticed except increasing the removal efficiency by about $7 \%$ as can be seen in Fig. $9 \mathrm{~b}$. Increasing air flow rate more than $1 \mathrm{~L} / \mathrm{min}$ leads to the problem of foam, and these results were in agreement with the finding of Rossi and Cilliers (2000).

\section{Comparison of TPFB and TPFB-S}

In order to evaluate the effectiveness of the spiral path, experiments were implemented with the same conditions using natural and activated form of adsorbent for treating virgin oil without using the spiral part in the unit, and their results are plotted in Fig. 10; the results demonstrated that the spiral path enhanced the removal efficiency by about $23 \%$ and $17 \%$ for natural and activated form of adsorbent, respectively. 


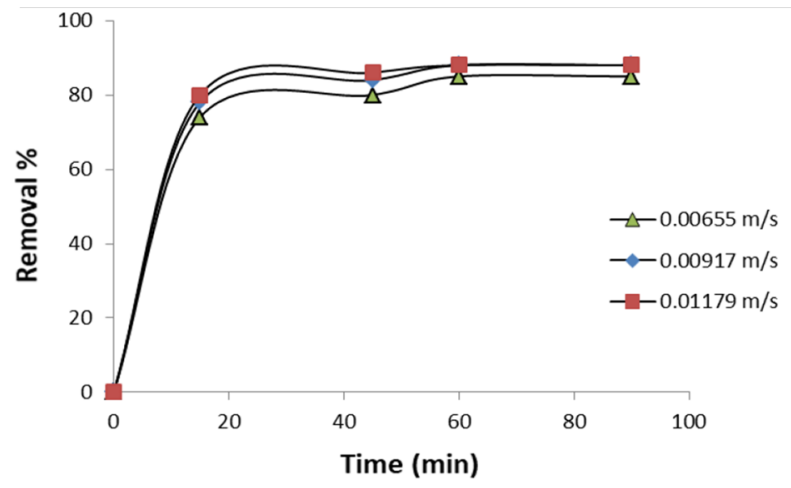

(a) Natural Ricinus-virgin oil

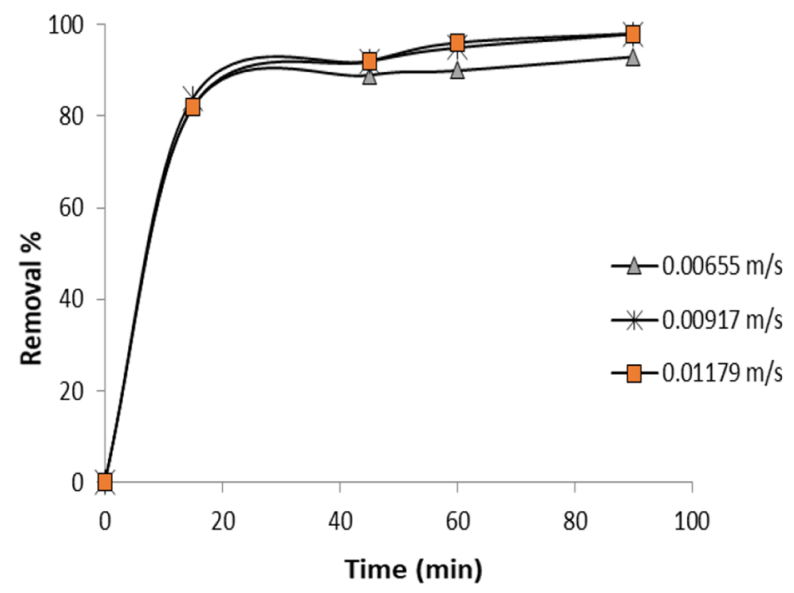

(c) Activated Ricinus-virgin oil

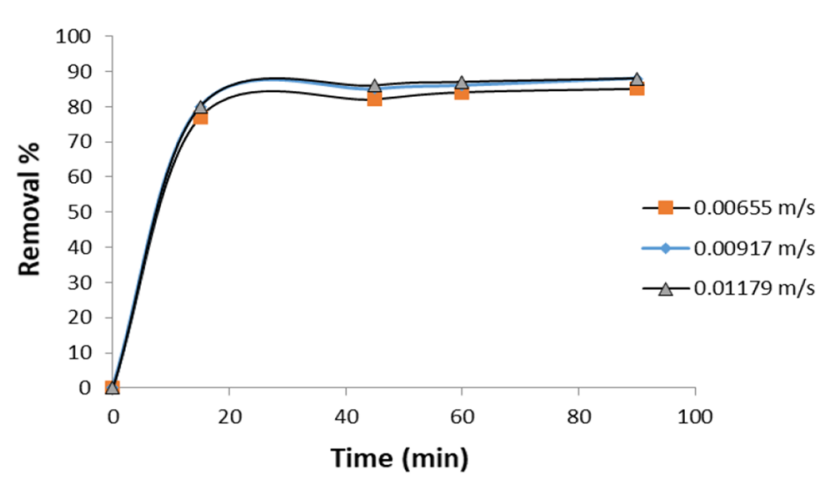

(b) Natural Ricinus-Waste oil

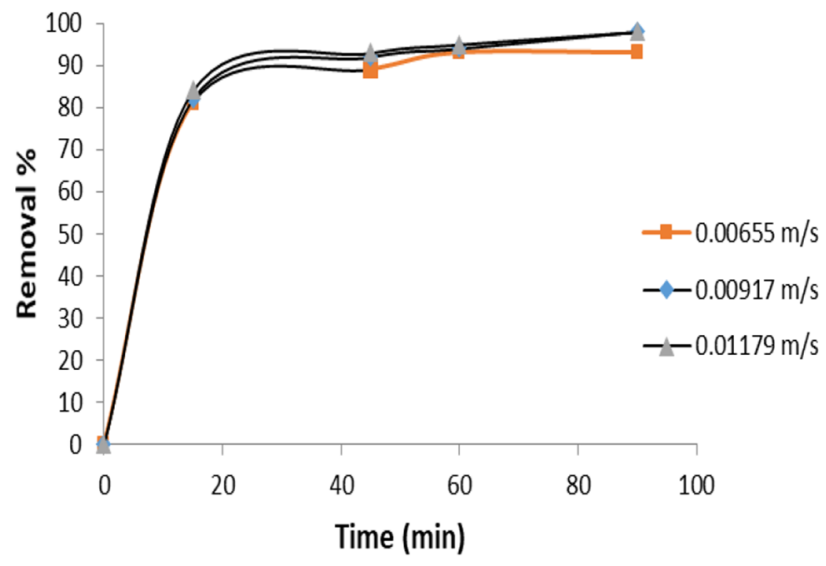

(d) Activated Ricinus-virgin oil

Fig. 8 Effect of liquid flow rate on the removal efficiency of oil emulsion by RC adsorbent

\section{Desorption process}

At the end of the adsorption process, the solution was transferred to the second stage in order to separate the adsorbent particles from the solution by using different hexane dosages $(50,100,150$ and 200) $\mathrm{mL} / \mathrm{L}$, and their results are plotted in Fig. 11, and as can be seen from this figure, the desorption process increased by increasing hexane concentration until reaching $150 \mathrm{~mL} / \mathrm{l}$; after that, it starts to decrease. The maximum oil recovery was $95 \%$ which had been achieved at $150 \mathrm{~mL} / \mathrm{L}$ of hexane concentration.

\section{Conclusions}

In the present study, a spiral unit was introduced into the conventional three-phase fluidized bed reactor (TPFB) and the new separation equipment was named threephase fluidized bed with spiral path reactor (TPFB-S). $\mathrm{RC}$ leaves were considered as low-cost adsorbent for the uptake oil emulsion from aqueous solution in TPFB-S unit. The characterization study of the materials done using the SEM images and FTIR analysis provided evidence for good biosorption of RC leaves related to the surface morphology and active groups. The biosorption performance of RC leaves for oil emulsion in TPFB-S reactor was remarkably influenced by changing the experimental conditions such as particle size, liquid and gas flow rate. The maximum removal efficiency was 91 and $98 \%$ at $150-300 \mu \mathrm{m}$ particle size, $3.5 \mathrm{~L} / \mathrm{min}$ liquid flow rate and $1 \mathrm{~L} / \mathrm{min}$ air flow rate for both virgin and waste oil by using natural and activated form of RC, respectively. Results show that adsorption-desorption process and the recovery efficiency increased from 50 to $95 \%$ when the concentration of hexane increased from 50 to $150 \mathrm{~mL} / \mathrm{L}$. The results indicated that the spiral unit can produce the upward water flow which may reduce the burden of water treatment in the conventional TPFB and enhanced the removal efficiency of virgin oil emulsion 


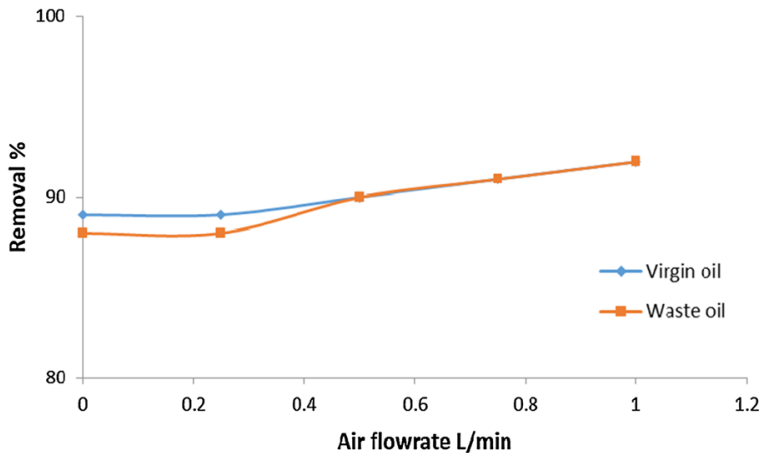

(a) natural RC adsorbent.

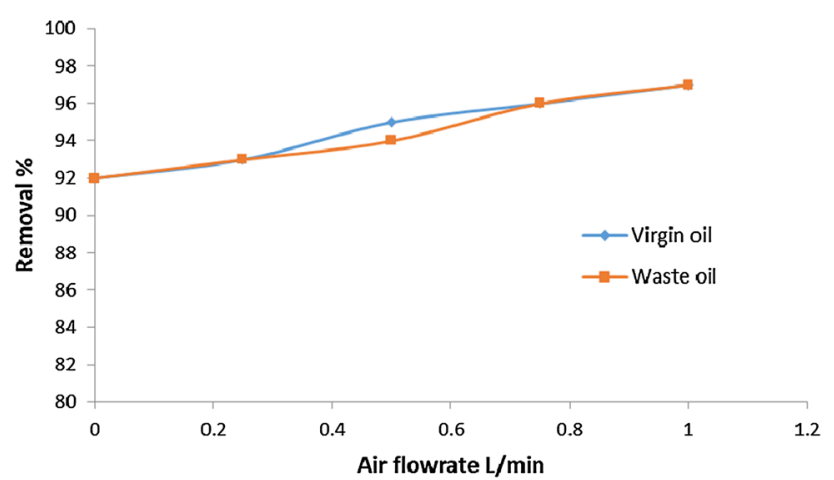

(b) Activated $\mathrm{RC}$ adsorbent

Fig. 9 Oil removal efficiency at different air flow rate by RC adsorbent

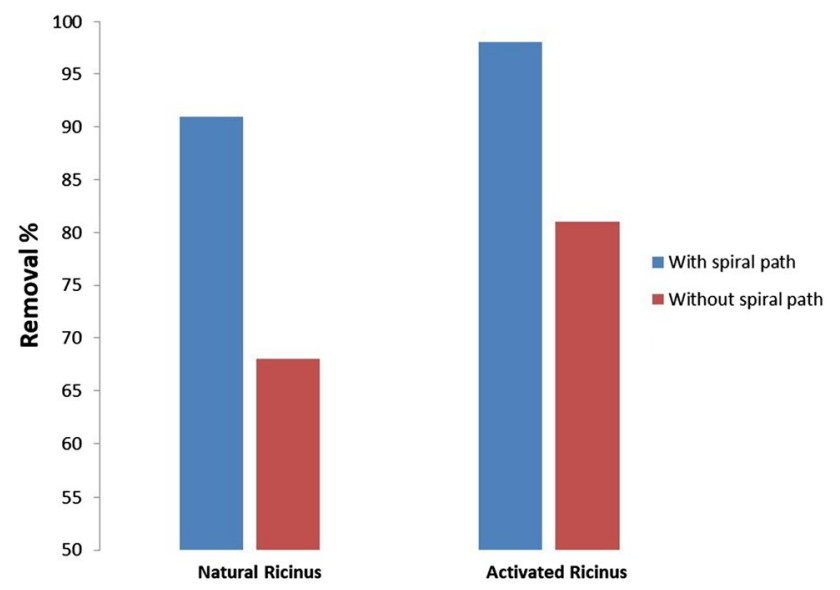

Fig. 10 Removal efficiency of oil emulsion by RC adsorbent in fluidized bed with and without spiral path

by about 23 and $17 \%$ for natural and activated form of RC leaves, respectively.

Funding This research did not receive any specific grant from funding in the public, commercial or not-for-profit sectors.

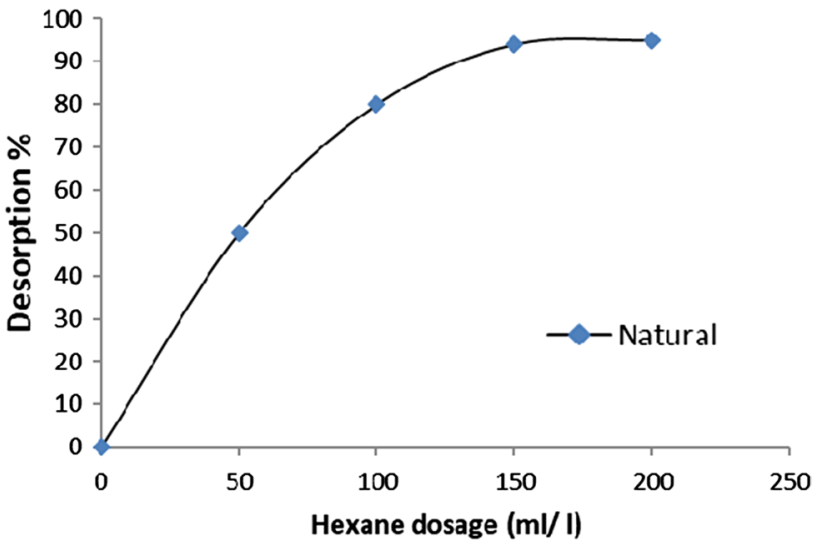

Fig. 11 Effect of hexane concentration on the removal efficiency of oil emulsion by RC adsorbent

\section{Compliance with ethical standards}

Conflict of interest All authors have participated in (a) conception and design or analysis and interpretation of the data; (b) drafting the article or revising it critically for important intellectual content; and (c) approval of the final version. This manuscript has not been submitted to, nor is under review at, another journal or other publishing venue. The authors have no affiliation with any organization with a direct or indirect financial interest in the subject matter discussed in the manuscript. On behalf of all authors, the corresponding author states that there is no conflict of interest.

Open Access This article is licensed under a Creative Commons Attribution 4.0 International License, which permits use, sharing, adaptation, distribution and reproduction in any medium or format, as long as you give appropriate credit to the original author(s) and the source, provide a link to the Creative Commons licence, and indicate if changes were made. The images or other third party material in this article are included in the article's Creative Commons licence, unless indicated otherwise in a credit line to the material. If material is not included in the article's Creative Commons licence and your intended use is not permitted by statutory regulation or exceeds the permitted use, you will need to obtain permission directly from the copyright holder. To view a copy of this licence, visit http://creativecommons.org/licenses/by/4.0/.

\section{References}

Abdul Hamid NS, Malek NAC, Mokhtar H, Mazlan WS, Tajuddin RM (2016) Removal of oil and grease form wastewater using natural adsorbents. Jurnal Teknol 78(5):97-102

Abel- Jabbar NM, Zubaidy EAHA, Mehrvar M (2010) Waste lubricating oil treatment by adsorption process using different adsorbents. Int J Chem Mol Eng 3(2):70-73

Alade AO, Jameel AT, Muyubi SA, Abdul Karim MI, Alam MZ (2011) Removal of oil and grease as emerging pollutants of concern (EPC) in wastewater stream. IIUM Eng J 12(4):161-169

Alwared AI, Faraj NS (2015) Coagulation-flotation process for removing oil from wastewater using sawdust+ bentonite. J Eng 21(6):62

Alwared AI, Jaeel AJ, Ismail ZZ (2020) New Application of ecofriendly biosorbent giant reed for removal of reactive dyes 
from water followed by sustainable path for recycling the dyesloaded sludge in concrete mixes. J Mater Cycles Waste Manage 22(4):1036-1046

Capodici M, Cosenza A, Trapani DD, Mannina G, Torregrossa M, Viviani G (2017) Treatment of oily wastewater with membrane bioreactor systems. Water 9:412. https://doi.org/10.3390/w9060 412

Cumming IW, Holdich RG, Smith ID (1999) The rejection of oil using an asymmetric metal microfilter to separate an oil in water dispersion. Water Res 33(17):3587-3594

Dechsiri C (2004) Particle transport in fluidized beds. Ph.D. Thesis, UMCG Research Database. University of Groningen, Groningen, The Netherlands

Hilal N, Ghannam MT, Anabtawi MZ (2001) Effect of bed diameter, distributor and Inserts on minimum fluidization velocity. Chem Eng Technol 24(2):161-164

Jaber WS, Alwared AI (2019) Removal of oil emulsion from aqueous solution by using ricinus communis leaves as adsorbent. SN Appl Sci. https://doi.org/10.1007/s42452-019-0970-x

Kamar FH, Mohammed AA, Faisal AAH, Nechifor AC, Nechifor G (2016) Biosorption of lead, copper and cadmium ions from industrial wastewater using fluidized bed of dry cabbage leaves. Rev Chim (Bucharest) 67(6):1039-1046

Khodadadi M, Al-Musawi TJ, Kamranifar M, Saghi MH, Hossein PA (2019) A comparative study of using barberry stem powder and ash as adsorbents for adsorption of humic acid. Environ Sci Pollut Res Int 26:26159-26169

Krstonosic V, Dokic L, Nikolic I, Dapcevic T, Hadnadjev M (2012) Influence of the sodium dodecyl sulphate (SDS) concentration on the disperse and rheological characteristics of oil-in-water emulsions stabilized by octenyl succinic anhydride modified StarchSDS mixtures. J Serb Chem Soc 77(1):83-94

Liang Z, Chen L, Alam MS, Zeraati RS, Stark C, Xu H, Harrison RM (2018) Comprehensive chemical characterization of lubricating oils used in modern vehicular engines utilizing GC $\times$ GC-TOFMS. Fuel 220:792-799

Mamoucha S, Tsafantakis N, Christodoulakis NS (2017) Structural and phytochemical investigation of the leaves of ricinus communis. Aust J Bot 65(1):58

Min JM, Jiang X, Wang F (2015) A mechanistic approach and response surface optimization of the removal of oil and grease from restaurant wastewater by electrocoagulation and electroflotation. Desalinat Water Treat 55(8):2044-2052

Mohammed AA, Najim AA (2020) Batch and circulated fluidized bed adsorption of nickel ions on algae: equilibrium, thermodynamic and mass transfer studies. Desalinat Water Treat. https://doi. org/10.5004/dwt.2020.26106

Mohammed AA, Brouersb F, Samaka IS, Al-Musawi TJ (2018) Role of $\mathrm{Fe} 3 \mathrm{O} 4$ magnetite nanoparticles used to coat bentonite in zinc (II) ions sequestration. Environ Nanotechnol Monitor Manag 10:17-27
Mustafa YA, Alwared AI, Ebrahim M (2013) Removal of oil from wastewater by advanced oxidation process/homogenous process. J Eng 19(6):686-694

Okiel K, El-Sayed M, El-Kady MY (2010) Treatment of oil-water emulsion adsorption onto activated carbon, bentonite and deposited carbon. Egypt J Petroleum 20:9-15

Osman DI, Attia SI, Tamam AR (2018) Recycling of used engine oil by different solvent. Egypt J Petrol 27(2):221-225

Parhamfar M, Bayat Z, ParhamfarShahian MMH, Hosseini SS (2018) Investigation of oil-in-water emulsions treatment by crude oil degrading bacteria and coagulation with cationic polyacrylamide. J Pet Environ Biotechnol 9:2

Riyanto, Ramadhan B, Wiyanti D (2018) Treatment of waste lubricating oil by chemical and adsorption process using butanol and kaolin. Mater Sci Eng 349(1):012054

Rossi S, Cilliers JJ (2000) Flowing foam bubble size control. IFAC Future Trends Autom Miner Metal Proc 33(22):443-446

Sulaymon AH, Mohammed AA, Al-Musawi TJ (2013) Column biosorption of lead, cadmium, copper, and arsenic ions onto Algae. J Bioproces Biotechniq 3(1):1-7

Sulaymon AH, Mohammed AA (2010) Separation and hydrodynamic performance of air-kerosene-water system by bubble column. Int J Chem Reactor Eng 8(1):1542-6580

Sulaymon AH, Mohammed AA and Al-Musawi, T J, 2013. Multicomponent Biosorption of Heavy Metals u1:944 I https://doi. org/10.1007/s42452-019-0970-xMsing Fluidized Bed of Algal Biomass. J Eng 19(4):469-484.

Tontiwachwuthkul P, Zubaidi I A, Rennie E, Schubert S, Seitz M and Selinger-Silva C, 2016. Remediation of Water from Waste Lubricating Oil Spill using Potato Peels, In: Proceeding of the 3rd Internattional Conference on Fluid Flow , Heat and Mass Transfer, Canada.

Travis MJ, Weisbrod N, Gross A (2008) Accumulation of oil and grease in soils irrigated with greywater and their potential role in soil water repellency. Sci Total Environ 394:68-74

USEPA, EPA (1999) Method 1664 revision A: N-hexane extractable material (HEM; oil and Grease) and silica gel treated N-hexane extractable material (SGT-HEM; non-polar Material) by extraction and gravimetry. United States Environmental Protection Agency, Washington DC

Vu TV, Papavassiliou DV (2018) Oil-water interfaces with surfactants : a systematic approach to determine coarse-grained model parameters. J Chem Phys. DOI 10(1063/1):5022798

Publisher's Note Springer Nature remains neutral with regard to jurisdictional claims in published maps and institutional affiliations. 